\title{
Quantitative Analysis of Design Ability of Culture and Creative Designers under Ethical Vision
}

\author{
Qing Tang \\ Jinshen College, Nanjing Audit University, Nanjing, China \\ Email: y1826432343y@163.com
}

How to cite this paper: Tang, Q. (2019). Quantitative Analysis of Design Ability of Culture and Creative Designers under Ethical Vision. Art and Design Review, 7, 237-252.

https://doi.org/10.4236/adr.2019.74019

Received: September 20, 2019

Accepted: November 12, 2019

Published: November 15, 2019

Copyright (อ 2019 by author(s) and Scientific Research Publishing Inc. This work is licensed under the Creative Commons Attribution International License (CC BY 4.0).

http://creativecommons.org/licenses/by/4.0/

\section{(c) (i) Open Access}

\begin{abstract}
The rapid development of Culture and creative industries has been promoted by "Internet+". However, the lack of talent of Culture and creativity has become a bottleneck restricting the development of industries. The development of industry can be aided by the quantitative evaluation system of the design ability of the designer, based on its monitoring, feedback and incentive functions. Based on the study of the existing competence evaluation index system, an evaluation index system for the design competence of creative designers of Culture was constructed by comprehensively investigating the three factors viz. design, ethics and sports. Subsequently, the subjective and objective combination weighting method was used to determine the weighted index of the design competence. Moreover, the fuzzy Topsis method was used to obtain the evaluation model, while the operability and scientificity of the evaluation index system and the evaluation method were verified by an example.
\end{abstract}

\section{Keywords}

Culture and Creativity, Design Ability, Quantitative Analysis, Subjective and Objective Combination Weighting Method, Fuzzy Topsis Method

\section{Introduction}

In the context of China's Internet+, "Internet + Wenchuang" combines the innovation of the Internet with the creativity of the cultural industry, and connects the creativity with the producers, users (consumers) and other related articles in a better way through the Internet platform (Xie et al., 2019) (Handy, 2016) (Guang, 2018). It helps to create a subject, thereby expanding the source of crea- 
tivity, improving production efficiency, strengthening community interaction, and merging social consensus (Tang, 2016) (Liu, 2018) (Lazzeretti et al., 2016). The development of cultural and creative industries is an inevitable choice to promote China's industrial structure optimization and industrial upgrading, and has an unmatched role in the transformation of economic development mode (Gundolf et al., 2018) (Wu \& Li, 2018) (Xu et al., 2016).

The core element of the development of cultural and creative industries is creative talents. The key to develop a cultural and creative industry is by cultivating creative entrepreneurs and specialized talents to provide a good external environment for the growth of creative talents (Moalosi et al., 2016) (Xu et al., 2016) (Kitsios et al., 2017) (Shi, 2013) (Petrova, 2018). Different localities have proposed to support colleges and universities to set up a number of cultural and creative industry-related majors or specializations, cultivate talents such as cultural and creative management, creative design, and cultivate talents of sports, culture, economy, management, science and technology, etc. The cultural and creative enterprises can jointly cultivate and establish a group of cultural and creative training, training bases integrating production, and education and research. Furthermore, they can actively introduce high-quality and innovative talents in the development and construction of cultural and creative industries at home and abroad, establish talent training mechanisms and training bases, and create an environment for good talent development and talent initiatives (Xie, 2018) (Li et al., 2016) (Absalyamov, 2015) (Holmes, 2013) (Chen \& Xu, 2016). In addition, from the perspective of design ethics, strengthening the protection of intellectual property rights, protecting the creative achievements of cultural creators and the legal income of property owners, and guiding the positive energy of cultural industry are also important aspects in the development of the cultural and creative industries. It can be seen from the above analysis that talents are crucial in the development of cultural and creative industries, and the designers responsible for creating cultural creations are the main players in the industry, and other practitioners and audiences in the industry affected by the design works. As one of the important components in the cultivation of talents in the cultural and creative industries, the design capability evaluation system is a key factor in the realization of the industrial upgrading target. A scientific and effective design capability evaluation system not only enables the designer to have an objective and comprehensive understanding of his own design capabilities, but also can guide the improvement of design capabilities through its monitoring and feedback functions. More importantly, through its incentive-oriented function it can encourage the innovative designers to actively participate in various cultural and creative activities (Liu, 2014) (Wang et al., 2011) (Wei, 2016) (Liang \& Huang, 2016).

Due to the intersection of disciplines and the uncertainty of evaluation indicators, the quantitative evaluation of the design ability of creative design in the Culture has not been studied. However, the current quantitative evaluation me- 
thods for ability of the students like enterprise innovation, morality, professional ability, and engineering ability have been reported previously (Biltekoff et al., 2014) (Brown \& Annis, 2011) (Zou \& Zhou, 2015) (Zhu \& Lei, 2012) (Yin, 2011) (Yun et al., 2010) (Lai, 2013). In addition, the negative design and false propaganda in the current design practice have appeared many times. Modern design is also full of negative factors such as money worship, hedonism and pornography (Wang, 2013) (Chance, 2012) (Maciintosh et al., 2015). Therefore, scholars have also issued a call for "designing ethics as the bottom line of design behavior" (Giaretta, 2013) (Gram-Hansen \& Ryberg, 2016). From the point of view of modern ethics, the fundamental reason for the lack of design ethics in various design works is due to the fact that the designers lack a systematic thinking about the design consequences in the design process ( $\mathrm{Li}, 2017)$ (Frías, 2013) (Cao \& Wu, 2014) (Leunes, 2012). In summary, the present research limits the evaluation object to the creative designers of Culture and considers the influence of design ethics and sports professional knowledge, while determining the design ability evaluation index set. Furthermore, it uses the subjective and objective weighted combination method to determine the weight of each index of the design ability, and then builds a design ability evaluation system suitable for creative designers of Culture.

\section{Construction of the Design Ability Index System of Culture Creative Designers}

On the basis of interpreting and combing relevant literatures, the design capability evaluation elements with higher frequency are selected as the candidate indicators based on the characteristics of the design subjects and the usual evaluation indicators of design capabilities. By the survey method, and invited universities, designers, audiences, etc. to conduct joint analysis and research. Ethical factors were added while designing the effective questionnaires. The elements with high recognition rate were selected as evaluation indicators from the reliability analysis. The alpha reliability coefficient method is used, that mainly considers the inherent reliability of the scale-whether there is a high internal consistency between the projects. It is generally believed that the reliability coefficient should be between 0 and 1 . If the reliability coefficient of the scale is above 0.9 , the reliability of the scale is good; if the reliability coefficient of the scale is between 0.8 and 0.9 , the amount is expressed. The reliability of the table is acceptable; if the reliability coefficient of the scale is between 0.7 and 0.8 , it indicates that some items of the scale need to be revised; if the reliability coefficient of the scale is below 0.7 , it means that some items of the scale need to be discarded. This study conducted a reliability analysis of the questionnaire through SPSS software. The consistency of each score is examined by the alpha coefficient of the primary indicator.

Further by the survey method, the universities and enterprise experts were invited to analyze and research together the selected evaluation indicators that were further classified and summarized, and feedback was obtained. In order to 
examine the interaction of the design ethical environment, the ethical level of the client and the audience was also added to the secondary indicators. Finally, according to the principles of hierarchy, comprehensiveness, conciseness, scientificity and operability, comprehensive design ability, and ethical level, a quantitative evaluation index system of design ethics was constructed, as shown in Table 1.

By the above method, the internal consistency analysis on all items of the entire scale is conducted, the total internal consistency reliability coefficient of the Table 1. Evaluation index system of design ability of Culture creative designers.

\begin{tabular}{|c|c|}
\hline Primary indicator & Secondary indicators \\
\hline \multirow[t]{6}{*}{ Knowledge accumulation } & Design basics \\
\hline & Design tool application level \\
\hline & Sports knowledge level \\
\hline & Interdisciplinary knowledge \\
\hline & Level of knowledge in the field of ethics \\
\hline & Design ethics level \\
\hline \multirow[t]{4}{*}{ Design thinking } & Observation and element refining ability \\
\hline & Imagination and design expression \\
\hline & Logic and framework construction capabilities \\
\hline & Appreciation of design works \\
\hline \multirow[t]{6}{*}{ Design skills } & Market research capability \\
\hline & Analytical ability \\
\hline & Planning organizational capacity \\
\hline & Design implementation capability \\
\hline & Humanized design presentation ability \\
\hline & Sports spirit connotation ability \\
\hline \multirow[t]{7}{*}{ Design personality and team } & Curiosity and interest \\
\hline & Self confidence \\
\hline & Independent thinking spirit \\
\hline & Team spirit \\
\hline & Critical spirit \\
\hline & Willpower \\
\hline & Communication skills \\
\hline \multirow[t]{2}{*}{ Design ethical environment } & The ethical level of the client \\
\hline & Audience ethical level \\
\hline \multirow[t]{4}{*}{ Design results } & Principal's recognition \\
\hline & Audience recognition \\
\hline & Peer review \\
\hline & Promotion of design works \\
\hline
\end{tabular}


questionnaire is 0.9074 , indicating that the reliability of the scale is good enough, and there is no need to modify the whole. All level indicators can be retained.

\section{Weight Determination of the Design Ability Index of Culture Creative Designers}

On the basis of the reconstructed design ability evaluation index system, the subjective entropy method is used to weight the evaluation index items, and the objective AHP method is used to determine the weight of the sub-criteria level indicators, and the weights obtained by the two methods are normalized. The weights of each index are obtained, the comment set is further determined, the fuzzy evaluation matrix is established, the fuzzy positive and negative ideal solutions are determined, and the distance and closeness of each evaluation object with the positive and negative ideal solutions are calculated, and the evaluation model is obtained.

\subsection{Determination of Weights}

The methods of weight determination mainly included the subjective weighting method and the objective weighting method. In the subjective weighting method, the weight of the index was obtained by the experts, based on the subjective judgment of the experience. The objective weighting method determined the weight according to the relationship between the original data. Both subjective and objective empowerment possessed their advantages and disadvantages ( $\mathrm{Wu}$ et al., 2015) (Dai et al., 2018). Therefore, this paper attempts to combine the subjective and objective weighting methods.

1) Objective entropy weight method

Using the entropy weight method to determine the weight of 29 secondary indicator items, the semantic value of the evaluation index was standardized (Beruvides et al., 2016), shown in Equation (1).

$$
C_{i j}^{*}=\operatorname{Con}+\frac{C_{i j}-\frac{\sum_{j=1}^{m} C_{j}}{n}}{\delta}(i=1,2, \cdots, n ; j=1,2, \cdots, m)
$$

where, $\delta$ is the standard deviation and $C o n$ is an arbitrary constant such that $C_{i j}$ $\geq 0$. The specific gravity $C_{i j}^{\#}$ and the entropy value $S_{j}$ of the normalized index value were calculated as per the formula is as shown in Equation (2).

$$
C_{i j}^{\#}=\frac{C_{i j}^{*}}{\sum_{j=1}^{m} C_{i j}^{*}} ; S_{j}=-\frac{\frac{1}{\ln (n)}}{\sum_{j=1}^{m} C_{i j}^{\#}\left[\ln \left(C_{i j}^{\#}\right)\right]} \quad(i=1,2, \cdots, n ; j=1,2, \cdots, m)
$$

The difference value $X_{j}$ was further calculated, and the weight $Q_{j}$ of each evaluation index was determined according to Equation (3).

$$
X_{j}=1-S_{j} ; Q_{j}=\frac{X_{j}}{\sum_{j=1}^{m} X_{j}}
$$


2) Subjective analytic hierarchy process

In this paper, the analytic hierarchy process was used to determine the weight of six first-level indicators and 29 second-level indicators. A total of 5 experts in the design field, ethical field, sports field, and education field were selected. The hierarchical analysis method was used to determine the hierarchical membership relationship. After the hierarchical structure was established, the factors in the same layer were compared and judged, and the judgment matrix $A$ was constructed (Yeoh \& Calantone, 2016).

$$
A=\left[\begin{array}{cccc}
a_{11} & a_{12} & \cdots & a_{1 m} \\
a_{21} & a_{22} & \cdots & a_{2 m} \\
\vdots & \vdots & \ddots & \vdots \\
a_{n 1} & a_{n 2} & \cdots & a_{n m}
\end{array}\right]
$$

The product $M_{i}$ of each row element of the judgment matrix $A$ was calculated using the $n$-th root $M_{i}$ and finally the weighted value $W_{j}$ normalized by each index was obtained, using Equation (4).

$$
\begin{gathered}
M_{i}=\prod_{i=1}^{n} a_{i j} \quad(j=1,2, \cdots, m) \\
\bar{W}_{j}=\sqrt[n]{M_{i}} \quad(i=1,2, \cdots, n ; j=1,2, \cdots, m) \\
W_{j}=\frac{\bar{W}_{j}}{\sum_{j=1}^{m} \bar{W}_{j}}
\end{gathered}
$$

3) Combination empowerment

By a comprehensive consideration of the two kinds of weighting methods, the weighting coefficients were determined by the subjective and objective weighting method, which were multiplied correspondingly, and finally normalized. The specific combination weighting formula is shown in Equation (5).

$$
z W_{j}=\frac{Q_{j} \times W_{j}}{\sum_{j=1}^{m} Q_{j} \times W_{j}}(j=1,2, \cdots, m)
$$

\subsection{Weight Determination Process}

From Equations (1)-(3), the weight of the second-level index of the design capability evaluation obtained by the objective method is shown in Table 2 .

In the next step, 5 experts were selected who scored each pair of indicators according to a scale of 1 - 5 scale. Subsequently, a judgment matrix was established, and the feature vector corresponding to the maximum eigenvalue $\lambda_{\max }$ was calculated by the product square root method. It was further normalized to determine the weight of each level factor as $W_{\dot{p}}$ the results are shown in Tables 3-9.

The results obtained by the formula 5 are shown in Table 10 .

\subsection{Analysis and Discussion of Weights}

It can be seen from the analysis of the weighted results from Table 10 that the design results was still an important indicator for evaluating the design ability of 
Table 2. Weight of design capability evaluation indicators obtained by objective method.

\begin{tabular}{|c|c|c|c|c|}
\hline Primary indicator $C_{i}$ & Secondary indicators $C_{i j}$ & $S_{i}$ & $X_{j}$ & $Q_{j}$ \\
\hline \multirow[t]{6}{*}{ Knowledge accumulation } & Design basics & 0.9829 & 0.0171 & 0.1825 \\
\hline & Design tool application level & 0.9859 & 0.0141 & 0.1503 \\
\hline & Sports knowledge level & 0.9852 & 0.0148 & 0.1578 \\
\hline & Interdisciplinary knowledge & 0.9835 & 0.0165 & 0.1755 \\
\hline & Level of knowledge in the field of ethics & 0.9826 & 0.0174 & 0.1852 \\
\hline & Design ethics level & 0.9861 & 0.0139 & 0.1486 \\
\hline \multirow[t]{4}{*}{ Design thinking } & Observation and element refining ability & 0.9842 & 0.0158 & 0.2645 \\
\hline & Imagination and design expression & 0.9840 & 0.0160 & 0.2676 \\
\hline & Logic and framework construction capabilities & 0.9871 & 0.0129 & 0.2157 \\
\hline & Appreciation of design works & 0.9849 & 0.0151 & 0.2523 \\
\hline \multirow[t]{6}{*}{ Design skills } & Market research capability & 0.9942 & 0.0058 & 0.0732 \\
\hline & Analytical ability & 0.9854 & 0.0146 & 0.1854 \\
\hline & Planning organizational capacity & 0.9841 & 0.0159 & 0.2018 \\
\hline & Design implementation capability & 0.9877 & 0.0123 & 0.1563 \\
\hline & Humanized design presentation ability & 0.9855 & 0.0145 & 0.1839 \\
\hline & Sports spirit connotation ability & 0.9843 & 0.0157 & 0.1994 \\
\hline \multirow{7}{*}{$\begin{array}{l}\text { Design personality and } \\
\text { team }\end{array}$} & Curiosity and interest & 0.9840 & 0.0160 & 0.1475 \\
\hline & Self confidence & 0.9858 & 0.0142 & 0.1311 \\
\hline & Independent thinking spirit & 0.9839 & 0.0161 & 0.1483 \\
\hline & Team spirit & 0.9835 & 0.0165 & 0.1523 \\
\hline & Critical spirit & 0.9853 & 0.0147 & 0.1361 \\
\hline & Willpower & 0.9845 & 0.0155 & 0.1435 \\
\hline & Communication skills & 0.9847 & 0.0153 & 0.1411 \\
\hline \multirow{2}{*}{$\begin{array}{l}\text { Design ethical } \\
\text { environment }\end{array}$} & The ethical level of the client & 0.9845 & 0.0155 & 0.4888 \\
\hline & Audience ethical level & 0.9838 & 0.0162 & 0.5112 \\
\hline \multirow[t]{4}{*}{ Design results } & Principal's recognition & 0.9867 & 0.0133 & 0.2390 \\
\hline & Audience recognition & 0.9849 & 0.0151 & 0.2713 \\
\hline & Peer review & 0.9864 & 0.0136 & 0.2434 \\
\hline & Promotion of design works & 0.9863 & 0.0137 & 0.2463 \\
\hline
\end{tabular}

Table 3. Judgment matrix of primary indicators.

\begin{tabular}{|c|c|c|c|c|c|c|}
\hline & $\begin{array}{c}\text { Knowledge } \\
\text { accumulation }\end{array}$ & Design thinking & Design skills & $\begin{array}{l}\text { Personality and } \\
\text { team }\end{array}$ & $\begin{array}{c}\text { Design ethical } \\
\text { environment }\end{array}$ & Design results \\
\hline Knowledge accumulation & 1 & & & & & \\
\hline Design thinking & 3 & 1 & & & & \\
\hline Design skills & 2 & 1 & 1 & & & \\
\hline Personality and team & $1 / 3$ & $1 / 3$ & $1 / 2$ & 1 & & \\
\hline Design ethical environment & $1 / 4$ & $1 / 4$ & $1 / 3$ & $1 / 2$ & 1 & \\
\hline Design results & $1 / 2$ & $1 / 2$ & 1 & 2 & 3 & 1 \\
\hline Weights $W$ & 0.168103 & 0.291162 & 0.211796 & 0.081612 & 0.067471 & 0.179855 \\
\hline
\end{tabular}


Table 4. Judgment matrix of knowledge accumulation.

\begin{tabular}{|c|c|c|c|c|c|c|}
\hline & $\begin{array}{l}\text { Design } \\
\text { basics }\end{array}$ & $\begin{array}{l}\text { Design tool } \\
\text { application level }\end{array}$ & $\begin{array}{c}\text { Sports knowledge } \\
\text { level }\end{array}$ & $\begin{array}{l}\text { Interdisciplinary } \\
\text { knowledge }\end{array}$ & $\begin{array}{l}\text { Level of knowledge } \\
\text { in the field of ethics }\end{array}$ & $\begin{array}{c}\text { Design } \\
\text { ethics level }\end{array}$ \\
\hline Design basics & 1 & & & & & \\
\hline Design tool application level & 3 & 1 & & & & \\
\hline Sports knowledge level & 2 & $1 / 2$ & 1 & & & \\
\hline Interdisciplinary knowledge & 1 & $1 / 3$ & 1 & 1 & & \\
\hline $\begin{array}{l}\text { Level of knowledge in the field of ethics } \\
\text { Interdisciplinary knowledge }\end{array}$ & 2 & 1 & 2 & 2 & 1 & \\
\hline Design ethics level & 2 & $1 / 2$ & 1 & 1 & $1 / 2$ & 1 \\
\hline Weights $W$ & 0.144959 & 0.251076 & 0.144959 & 0.110145 & 0.219717 & 0.129144 \\
\hline
\end{tabular}

Table 5. Judgment matrix of design thinking.

\begin{tabular}{ccccc}
\hline & $\begin{array}{c}\text { Observation and } \\
\text { element refining ability }\end{array}$ & $\begin{array}{c}\text { Imagination and design } \\
\text { expression }\end{array}$ & $\begin{array}{c}\text { Logic and framework } \\
\text { construction capabilities }\end{array}$ & $\begin{array}{c}\text { Appreciation of } \\
\text { design works }\end{array}$ \\
\hline Observation and element refining ability & 1 & 1 & & \\
Imagination and design expression & $1 / 2$ & 2 & $1 / 3$ & 1 \\
Logic and framework construction capabilities & 1 & 2 & 0.257359 & 0.184575 \\
Appreciation of design works & 1 & 0.353799 & \\
Weights $W$ & 0.204266 & &
\end{tabular}

Table 6. Judgment matrix of design skills.

\begin{tabular}{|c|c|c|c|c|c|c|}
\hline & $\begin{array}{l}\text { Market research } \\
\text { capability }\end{array}$ & $\begin{array}{l}\text { Analytical } \\
\text { ability }\end{array}$ & $\begin{array}{c}\text { Planning } \\
\text { organizational } \\
\text { capacity }\end{array}$ & $\begin{array}{c}\text { Design } \\
\text { implementation } \\
\text { capability }\end{array}$ & $\begin{array}{l}\text { Humanized design } \\
\text { presentation ability }\end{array}$ & $\begin{array}{l}\text { Sports spirit } \\
\text { connotation } \\
\text { ability }\end{array}$ \\
\hline Market research capability & 1 & & & & & \\
\hline Analytical ability & $1 / 2$ & 1 & & & & \\
\hline Planning organizational capacity & $1 / 3$ & $1 / 2$ & 1 & & & \\
\hline Design implementation capability & $1 / 2$ & 1 & $1 / 2$ & 1 & & \\
\hline Humanized design presentation ability & 1 & 2 & $1 / 2$ & 1 & 1 & \\
\hline Sports spirit connotation ability & $1 / 3$ & 2 & 1 & $1 / 2$ & $1 / 2$ & 1 \\
\hline Weights $W$ & 0.176199 & 0.305186 & 0.096966 & 0.124591 & 0.166347 & 0.130711 \\
\hline
\end{tabular}

Table 7. Personality and team judgment matrix.

\begin{tabular}{|c|c|c|c|c|c|c|c|}
\hline & $\begin{array}{c}\text { Curiosity and } \\
\text { interest }\end{array}$ & $\begin{array}{c}\text { Self } \\
\text { confidence }\end{array}$ & $\begin{array}{l}\text { Independent } \\
\text { thinking spirit }\end{array}$ & Team spirit & $\begin{array}{c}\text { Critical } \\
\text { spirit }\end{array}$ & Willpower & $\begin{array}{c}\text { Communication } \\
\text { skills }\end{array}$ \\
\hline Curiosity and interest & 1 & & & & & & \\
\hline Self confidence & 2 & 1 & & & & & \\
\hline Independent thinking spirit & 3 & 2 & 1 & & & & \\
\hline Team spirit & 2 & $1 / 2$ & 2 & 1 & & & \\
\hline Critical spirit & $1 / 2$ & $1 / 2$ & $1 / 2$ & $1 / 3$ & 1 & & \\
\hline Willpower & 2 & 1 & 2 & 2 & 2 & 1 & \\
\hline Communication skills & 3 & 2 & 1 & 1 & 2 & $1 / 2$ & 1 \\
\hline Weights $W$ & 0.113259 & 0.160173 & 0.205806 & 0.134689 & 0.059983 & 0.179788 & 0.146298 \\
\hline
\end{tabular}


Table 8. Judgment matrix of design ethical environment.

\begin{tabular}{ccc}
\hline & The ethical level of the client & Audience ethical level \\
\hline The ethical level of the client & 1 & 1 \\
Audience ethical level & 3 & 0.633975 \\
Weights $W$ & 0.366025 & \\
\hline
\end{tabular}

Table 9. Judgment matrix of design results.

\begin{tabular}{ccccc}
\hline & $\begin{array}{c}\text { Principal's } \\
\text { recognition }\end{array}$ & $\begin{array}{c}\text { Audience } \\
\text { recognition }\end{array}$ & Peer review & $\begin{array}{c}\text { Promotion of } \\
\text { design works }\end{array}$ \\
\hline Principal's recognition & 1 & & & \\
Audience recognition & 2 & 1 & 1 & \\
Peer review & 2 & 2 & $1 / 3$ & 1 \\
Promotion of design works & $1 / 2$ & $1 / 2$ & 0.326845 & 0.110627 \\
Weights $W$ & 0.205900 & 0.356629 & & \\
\hline
\end{tabular}

the designers. All experts believed that their weights were high. The weight of design thinking and design skills was higher than that of knowledge accumulation and personality team, indicating that the evaluation of design ability paid a more attention to the broadening of thinking and its skill factors. Knowledge accumulation and habits can be acquired. For the design ethical environment, the weight was the lowest, because the design ethical environment was not much different for the individual designers.

The analysis of the secondary indicators by the weight calculation results in Table 10 can be further seen as:

1) In the accumulation of knowledge, the impact of various knowledge levels on the design capabilities was basically the same. Among them, the knowledge level in the ethical field possessed a highest weight value. It is important to incorporate the knowledge level in the ethical field into the evaluation system to accurately evaluate the ability. The corresponding design ethics level had a higher weight, and the ethical total knowledge level occupied the knowledge accumulation over $40 \%$ weight, indicating that the current design field paid more attention to the ethical influence, hoping to embody the humanized design and convey correct values in the design. The level of knowledge in the sports field was ranked among the various levels of knowledge accumulation, and the Culture creative design was also an indispensable accumulation. The cross-disciplinary knowledge level was the lowest, due to the difficulty in learning the interdisciplinary knowledge yin daily learning and difficulty in its quantification. Therefore, the survey sample possessed a lower knowledge score in the field.

2) In the indicators of design thinking, the observation and element refinement, and the imagination and design expression ability were both high, and also met the requirements for the basic quality of the designer.

3) In terms of the design skill indicators, the market research ability was much 
Table 10. Design ability evaluation indicators after combined empowerment.

\begin{tabular}{|c|c|c|c|c|c|}
\hline Primary indicator $C_{i}$ & Weights & Secondary indicators $C_{i j}$ & $Q_{j}$ & $W_{j}$ & $z W_{j}$ \\
\hline \multirow{7}{*}{ Knowledge accumulation } & \multirow{6}{*}{0.1701} & Design basics & 0.1825 & 0.1593 & 0.1732 \\
\hline & & Design tool application level & 0.1503 & 0.1593 & 0.1427 \\
\hline & & Sports knowledge level & 0.1578 & 0.1593 & 0.1498 \\
\hline & & Interdisciplinary knowledge & 0.1755 & 0.1210 & 0.1266 \\
\hline & & Level of knowledge in the field of ethics & 0.1852 & 0.2415 & 0.2665 \\
\hline & & Design ethics level & 0.1486 & 0.1593 & 0.1411 \\
\hline & \multirow{4}{*}{0.2946} & Observation and element refining ability & 0.2645 & 0.2704 & 0.2840 \\
\hline \multirow{3}{*}{ Design thinking } & & Imagination and design expression & 0.2676 & 0.2704 & 0.2873 \\
\hline & & Logic and framework construction capabilities & 0.2157 & 0.2146 & 0.1838 \\
\hline & & Appreciation of design works & 0.2523 & 0.2443 & 0.2448 \\
\hline \multirow{6}{*}{ Design skills } & \multirow{6}{*}{0.2143} & Market research capability & 0.0732 & 0.1210 & 0.0513 \\
\hline & & Analytical ability & 0.1854 & 0.1711 & 0.1838 \\
\hline & & Planning organizational capacity & 0.2018 & 0.1921 & 0.2245 \\
\hline & & Design implementation capability & 0.1563 & 0.1592 & 0.1442 \\
\hline & & Humanized design presentation ability & 0.1839 & 0.1732 & 0.1845 \\
\hline & & Sports spirit connotation ability & 0.1994 & 0.1831 & 0.2115 \\
\hline \multirow{7}{*}{ Design personality and team } & \multirow{7}{*}{0.0825} & Curiosity and interest & 0.1475 & 0.1192 & 0.1228 \\
\hline & & Self confidence & 0.1311 & 0.1192 & 0.1091 \\
\hline & & Independent thinking spirit & 0.1483 & 0.1502 & 0.1556 \\
\hline & & Team spirit & 0.1523 & 0.1418 & 0.1508 \\
\hline & & Critical spirit & 0.1361 & 0.1192 & 0.1133 \\
\hline & & Willpower & 0.1435 & 0.1893 & 0.1897 \\
\hline & & Communication skills & 0.1411 & 0.1607 & 0.1584 \\
\hline \multirow{3}{*}{ Design ethical environment } & \multirow{2}{*}{0.0682} & The ethical level of the client & 0.4888 & 0.4142 & 0.4033 \\
\hline & & Audience ethical level & 0.5112 & 0.5857 & 0.5966 \\
\hline & \multirow{4}{*}{0.1701} & Principal's recognition & 0.2390 & 0.2214 & 0.2103 \\
\hline \multirow{3}{*}{ Design results } & & Audience recognition & 0.2713 & 0.3132 & 0.3376 \\
\hline & & Peer review & 0.2434 & 0.2790 & 0.2698 \\
\hline & & Promotion of design works & 0.2463 & 0.1862 & 0.1822 \\
\hline
\end{tabular}

lower than other indicators, indicating that the designer's design style was less affected by the market trends, and the sports spirit connotation presentation ability had a high impact on the design ability, which was consistent with the Culture.

4) The design personality was basically the same as the weight of each index in the team. The independent thinking spirit and the willpower had the highest weight, which further confirms the difference between design and engineering. The personal quality of the designer was more favorable than the team quality. 
5) In the indicators of the design ethical environment, the ethical level of the audience was more affected than the ethical level of the client, emphasizing the view of the scholars that the design should serve the general public.

6) The evaluation of the design results was similar to the design environment. The recognition of the audience was the highest, and the recognition of the peers also affected the designer's reflection on their own design works.

\section{Evaluation and Application of the Design Ability of Culture Creative Designers}

\subsection{Construction of the Evaluation Model}

The TOPSIS method used in the evaluation model is a multi-objective decision-making method (Chen et al., 2014) (Liu \& Zhang, 2017) (Peng et al., 2016). Compared with the traditional multi-statistic method for evaluating problems, it has the characteristics of intuitive analysis principle, simple calculation and little requirement for sample size. In this paper, based on the combination weight of the evaluation index and the initial fuzzy evaluation matrix, the weighted decision matrix is further constructed; the ideal value and the non-ideal value vector are constructed; the distance and closeness of each evaluation object and the positive and negative ideal solutions are calculated, and the design capability level of each evaluation object is calculated and can be sorted according to the size of the closeness value. The model construction process of the method included the following four processes:

1) Establishment of a fuzzy evaluation matrix

According to the comment set, an initial fuzzy evaluation matrix was constructed, where $X_{i j}$ is the semantic value of the $j$ th evaluation index of the $i$-th evaluation object.

$$
X_{i j}=\left[\begin{array}{cccc}
X_{11} & X_{12} & \cdots & X_{1 m} \\
X_{21} & X_{22} & \cdots & X_{2 m} \\
\vdots & \vdots & \ddots & \vdots \\
X_{n 1} & X_{n 2} & \cdots & X_{n m}
\end{array}\right] \quad(i=1,2, \cdots, n ; j=1,2, \cdots, m)
$$

2) Establishment of a weighting matrix

The weighted decision matrix was constructed according to the combined weight of the evaluation index and the initial fuzzy evaluation matrix, according to Equation (6).

$$
\begin{gathered}
\lambda=\left[\begin{array}{cccc}
\lambda_{11} & \lambda_{12} & \cdots & \lambda_{1 m} \\
\lambda_{21} & \lambda_{22} & \cdots & \lambda_{2 m} \\
\vdots & \vdots & \ddots & \vdots \\
\lambda_{n 1} & \lambda_{n 2} & \cdots & \lambda_{n m}
\end{array}\right] \\
\lambda_{i j}=z W_{j} * X_{i j} \quad(i=1,2, \cdots, n ; j=1,2, \cdots, m)
\end{gathered}
$$

3) Determination of the fuzzy positive and negative ideal solution

The ideal value $\lambda^{+}$and the non-ideal value vector $\lambda^{-}$were constructed 
using Equation (7).

$$
\begin{aligned}
& \lambda^{+}=\left(\lambda_{1}^{+}, \lambda_{2}^{+}, \cdots, \lambda_{m}^{+}\right) \\
& \lambda^{-}=\left(\lambda_{1}^{-}, \lambda_{2}^{-}, \cdots, \lambda_{m}^{-}\right) \\
& \lambda_{j}^{+}=\max \left(\lambda_{1 j}, \lambda_{2 j}, \cdots, \lambda_{n j}\right) \\
& \lambda_{j}^{-}=\min \left(\lambda_{1 j}, \lambda_{2 j}, \cdots, \lambda_{n j}\right)
\end{aligned}
$$

4) Calculation of the distance and closeness of each evaluation object from positive and negative ideal solutions

The Euclidean distance between each index and the ideal value and the non-ideal value is $Z_{i}^{+}$and $Z_{i}^{-}$according to Equation (8) and the closeness of each evaluation object to the ideal solution is recorded as $\omega_{i}$.

$$
\begin{gathered}
Z_{i}^{+}=\sqrt{\sum_{j=1}^{m}\left(\lambda_{i j}-\lambda_{j}^{+}\right)^{2}} ; Z_{i}^{-}=\sqrt{\sum_{j=1}^{m}\left(\lambda_{i j}-\lambda_{j}^{-}\right)^{2}} \\
\omega_{i}=\frac{Z_{i}^{-}}{Z_{i}^{-}+Z_{i}^{+}}
\end{gathered}
$$

The larger the value of $\omega_{i}$, the closer was the design ability level of the evaluation object to the ideal value, and the design ability level of each evaluation object was sorted according to the size of the $\omega_{i}$ value.

\subsection{Analysis of the Application Effect of the Evaluation Model}

By applying the obtained evaluation model to the evaluation of design ability of three designers from different companies engaged in the Culture creative design, the scientific and practicality of the whole evaluation index system and evaluation method was verified in the form of examples. The results obtained are shown in Table 11.

As can be seen from Table 11, the design ability of the designer Duxx is ranked first, and the score obtained by the evaluation model is higher than that of other designers. The main reason is that the designer has been the chief designer of a company for many years, and his abilities have been obtained. It has won praises from peers and customers, and has won various awards in design. Through various weights, its innovation ability ranks first in line with other evaluation systems; it is worth noting that Chen $\times \times$ designer, the designer's design thinking And the design skills are general, but its design concept has always advocated green simplicity, its design ethics ability is more prominent, and the weighted design ability ranking has been greatly improved, which also shows

Table 11. Quantitative calculation of design ability of evaluation objects.

\begin{tabular}{ccccc}
\hline Number & Company & Name & $\omega_{i}$ & Sort \\
\hline 1 & A & Li $\times \times$ & 0.5824 & 3 \\
2 & B & Chen $\times \times$ & 0.6620 & 2 \\
3 & C & Duxx & 0.7016 & 1 \\
\hline
\end{tabular}


that design ethics has an obvious effect on the improvement of design ability. It can be showed from Table 11 that the model constructed in this paper could quantitatively describe the design ability of the creative designers engaged in the Culture, and the calculated results were consistent with the qualitative judgment. Currently, the design ability of the designers engaged in the Culture and creativity is generally not high. It should be upgraded from multiple angles to make up for the lack of design ability and promote the overall improvement of the creative design level of the Culture.

\section{Conclusion}

In the present work, initially an index system was constructed for the quantitative evaluation of the design ability of creative designers in the Culture. In the process of construction, the design ethics was innovatively incorporated into the index system, and the index system of the new system was obtained. Combining the weighting method with the fuzzy Temple's evaluation method, and considering the inaccuracy and ambiguity of the evaluation process of different professional background evaluation objects, the semantic value was used to replace the index level, and the evaluation object was used between the positive and negative ideal solutions. The relative closeness was used as the final evaluation criteria. The constructed model ascertained the rationality and scientificity of the index system construction; thus it possesses a significant practical value and can provide a reference for the quantitative evaluation of the design ability of designers in other industries.

\section{Acknowledgements}

The research was financially supported by the 2018 Jiangsu University Philosophy and Social Science Research Project (Based on Cloud Platform for the Construction and Sharing of Art Teaching Resources) (2018SJA2176).

\section{Conflicts of Interest}

The author declares no conflicts of interest regarding the publication of this paper.

\section{References}

Absalyamov, T. (2015). The Influence of Cultural and Sport Mega-Events on Sustainable Development of the City. Procedia-Social and Behavioral Sciences, 188, 197-201. https://doi.org/10.1016/j.sbspro.2015.03.372

Beruvides, G., Quiza, R., \& Haber, R. E. (2016). Multi-Objective Optimization Based on an Improved Cross-Entropy Method. A Case Study of a Micro-Scale Manufacturing Process. In Information Sciences (pp. 334-335). Berlin: Springer.

https://doi.org/10.1016/j.ins.2015.11.040

Biltekoff, C., Mudry, J., \& Kimura, A. H. (2014). Interrogating Moral and Quantification Discourses in Nutritional Knowledge. Gastronomica: The Journal of Food \& Culture, 14, 17-26. https://doi.org/10.1525/gfc.2014.14.3.17 
Brown, D. M., \& Annis, L. (2011). Moral Development Level and Religious Behavior. Psychological Reports, 43, 1230.

Cao, Q., \& Wu, L. H. (2014). The Application of Modern Technology in Sports Promotion. Advanced Materials Research, 926-930, 4122-4125. https://doi.org/10.4028/www.scientific.net/AMR.926-930.4122

Chance, H. (2012). Mobilising the Modern Industrial Landscape for Sports and Leisure in the Early Twentieth Century. International Journal of the History of Sport, 29, 1600-1625. https://doi.org/10.1080/09523367.2012.708607

Chen, H. W., \& Xu, Z. Y. (2016). International Development and Literature Review of Creative Industry on Culture. Journal of Hunan City University (Natural Science), 25, 81-82.

Chen, K.-H., Liao, C.-N., \& Wu, L.-C. (2014). A Selection Model to Logistic Centers Based on TOPSIS and MCGP Methods: The Case of Airline Industry. Journal of Applied Mathematics, 2014, Article ID: 470128. https://doi.org/10.1155/2014/470128

Dai, N. T., Xi, K., \& Tang, G. (2018). Differential Weighting of Objective versus Subjective Measures in Performance Evaluation: Experimental Evidence. European Accounting Review, 27, 129-148.

Frías, F. J. L. (2013). The Challenges of Modern Sport to Ethics. From Doping to Cyborgs. Journal of the Philosophy of Sport, 41, 413-417.

Giaretta, E. (2013). Ethical Product Innovation: In Praise of Slowness. TQM Magazine, 17, 161-181.

Gram-Hansen, S. B., \& Ryberg, T. (2016). From Participatory Design and Ontological Ethics, towards an Approach to Constructive Ethics. ACM Sigcas Computers \& Society, 45, 147-153. https://doi.org/10.1145/2874239.2874260

Guang, Y. (2018). Sustainable Development of Cultural and Creative Industry in the Internet Environment. Ecological Economy, 3, 221-228.

Gundolf, K., Jaouen, A., \& Gast, J. (2018). Motives for Strategic Alliances in Cultural and Creative Industries. Creativity \& Innovation Management, 27, 148-160. https://doi.org/10.1111/caim.12255

Handy, R. (2016). Expected Job Creation across the Cultural Industries: A Sectoral Division and Its Implications for Cultural Policy. The International Journal of Cultural Policy, 24, 45-67.

Holmes, J. (2013). Research on Organization Model and Integration of College Sports Industry in China. Sports Science Research, 17, 16-18.

Kitsios, F., Champipi, E., \& Grigoroudis, E. (2017). Cultural and Creative Industries Innovation Strategies for New Service Development Using MCDA. In E. Grigoroudis, \& M. Doumpos (Eds.), Operational Research in Business and Economics (pp. 69-84). Berlin: Springer. https://doi.org/10.1007/978-3-319-33003-7_4

Lai, Y. X. (2013). Evaluation of Engineering Ability of Information Security Undergraduates. Research and Exploration in Laboratory, 32, 150-153+193.

Lazzeretti, L., Capone, F., \& Seçilmiş, I. E. (2016). In Search of a Mediterranean Creativity. Cultural and Creative Industries in Italy, Spain and Turkey. European Planning Studies, 24, 568-588. https://doi.org/10.1080/09654313.2015.1082979

Leunes, A. (2012). Exercise and Sport Psychology. In V. Ramachandran (Ed.), Encyclopedia of Human Behavior (pp. 132-141). Cambridge, MA: Academic Press. https://doi.org/10.1016/B978-0-12-375000-6.00343-8

Li, J. C., Li, Y. B., \& Tang, J. G. (2016). Discussing on the Relationship between Sports Cultural Creative Industry and Modern Urban Development. Contemporary Sports 
Technology, 6, 143-145.

Li, S. (2017). Ethics and Market Design. Mpra Paper. https://doi.org/10.2139/ssrn.3026961

Liang, X., \& Huang, S. (2016). Evaluation System Research of Core Competitiveness of Sports Products and Growing Environment. Journal of Computational and Theoretical Nanoscience, 13, 9733-9737. https://doi.org/10.1166/jctn.2016.5916

Liu, C. H. S. (2018). Examining Social Capital, Organizational Learning and Knowledge Transfer in Cultural and Creative Industries of Practice. Tourism Management, 64, 258-270. https://doi.org/10.1016/j.tourman.2017.09.001

Liu, F., \& Zhang, W. G. (2017). TOPSIS-Based Consensus Model for Group Decision-Making with Incomplete Interval Fuzzy Preference Relations. IEEE Transactions on Cybernetics, 44, 1283-1294.

Liu, W. (2014). Study on the System Design of Sports Public Service Performance Evaluation. In Frontier and Future Development of Information Technology in Medicine and Education (pp. 1143-1148). Lecture Notes in Electrical Engineering, Berlin: Springer. https://doi.org/10.1007/978-94-007-7618-0_114

Maciintosh, E., Couture, A. L., \& Spence, K. (2015). Management Challenges in Delivering an International Sport and Development Program. Sport, Business and Management: An International Journal, 5, 276-296. https://doi.org/10.1108/SBM-07-2012-0028

Moalosi, R., Setlhatlhanyo, K., \& Sealetsa, O. J. (2016). Cultural Memory, an Asset for Design-Driven Innovation within the Creative Industries Sector: Lessons for Design Education. Design \& Technology Education, 21, 9-22.

Peng, W., Zhu, Z., \& Wang, Y. (2016). A Novel Hybrid MCDM Model Combining the SAW, TOPSIS and GRA Methods Based on Experimental Design. Information Sciences, $345,27-45$.

Petrova, L. (2018). Cultural Entrepreneurship in the Context of Spillovers within the Cultural and Creative Industries. In Entrepreneurship in Cultural and Creative Industries (pp. 197-212). Berlin: Springer. https://doi.org/10.1007/978-3-319-65506-2_11

Shi, C. (2013). The National Tradition Sports in Constructing the Shanxi University Campus Culture Function. Sports Forum, 5, 92-94.

Tang, Y.K. (2016). Cultural Industry Goes Global. Beijing Review.

Wang, J., Zhao, S., \& Wei, P. (2011). Evaluation Indicators System of Sports Public Services Performance of Local Government. Journal of Shenyang Sport University, No. 2, $1-3+7$.

Wang, Z. Y. (2013). Modern Design: Industrial Technology, Engineering and Culture. Advanced Materials Research, 655-657, 2065-2068. https://doi.org/10.4028/www.scientific.net/AMR.655-657.2065

Wei, C. (2016). International Sports Central City Public Sports Service Fuzzy Comprehensive Evaluation System Research. Journal of Computational \& Theoretical Nanoscience, 13, 10174-10177. https://doi.org/10.1166/jctn.2016.6236

Wu, M., \& Li, Q. (2018). Impact of Cultural and Creative Industries on Regional Economic Development in China-A Spatial Econometric Approach. Research in World Economy, 9, 47-60. https://doi.org/10.5430/rwe.v9n1p46

Wu, X., Chen, L., \& Pang, S. (2015). A Paratactic Subjective-Objective Weighting Methods and SVM Risk Assessment Model Applied in Textile and Apparel Safety. International Journal of Quality \& Reliability Management, 32, 472-485.

https://doi.org/10.1108/IJQRM-06-2013-0102

Xie, J. (2018). A Comparative Study on Folk Culture and Creative Industry in Fujian and 
Taiwan. Sports Science Research, 22, 1-6.

Xie, X., Xie, X., \& Martínez-Climent, C. (2019). Identifying the Factors Determining the Entrepreneurial Ecosystem of Internet Cultural Industries in Emerging Economies. International Entrepreneurship and Management Journal, 15, 503-522. https://doi.org/10.1007/s11365-019-00562-Z

Xu, Y. H., Lu, L., \& Yao, Z. X. (2016). Culture and Creative Industry in China: Critical Review on the Current Research Trends and Future Development. International Journal of Innovation \& Technology Management, 13, 1-24.

https://doi.org/10.1142/S0219877016400162

Yeoh, P. L., \& Calantone, R. J. (2016). An Application of the Analytical Hierarchy Process to International Marketing: Selection of a Foreign Distributor. Journal of Global Marketing, 8, 39-65.

Yin, W. (2011). Moral Quantification Evaluation Studies: State of Art and Its Problems. Higher Education Development and Evaluation, 27, 98-103+121.

Yun, D., Yong, N., \& Zhu, S.-R. (2010). Application of Delphi Method in Quantitative Checklist of Occupational Hazard Control. Journal of Environmental \& Occupational Medicine, 27, 371-373.

Zhu, Y., \& Lei, H. (2012). Fuzzy AHP Analysis on Enterprises' Independent Innovation Capability Evaluation. Physics Procedia, 24, 1285-1291.

https://doi.org/10.1016/j.phpro.2012.02.192

Zou, H., \& Zhou, H. Y. (2015). The Study of the Construction of Innovation Ability Evaluation System for Postgraduates in Science and Engineering Majors. Research in Higher Education of Engineering, 4, 126-128+153. 